\title{
Congenital heart disease and thyroid dysfunction in Down syndrome reported at Children's Hospital, Lahore, Pakistan
}

\author{
Muhammad Yaqoob ${ }^{1}$, Jaida Manzoor², Syed Najam Hyder ${ }^{3}$, Masood Sadiq ${ }^{3}$ \\ ${ }^{1}$ University Institute of Public Health, University of Lahore, 1-km Defense Road, Lahore; Departments of ${ }^{2}$ Pediatric \\ Endocrinology and ${ }^{3}$ Pediatric Cardiology, The Children's Hospital and the Institute of Child Health, Lahore, Pakistan. \\ E-mail: yaqoobchich@yahoo.com \\ Received: 15th February 2018, Revised: 2nd May 2018, 27th July 2018, 1st November 2018, 17th December \\ 2018, 13th January 2019, Accepted: 17th January 2019
}

SUMMARY: Yaqoob M, Manzoor J, Hyder SN, Sadiq M. Congenital heart disease and thyroid dysfunction in Down syndrome reported at Children's Hospital, Lahore, Pakistan. Turk J Pediatr 2019; 61: 915-924.

Down syndrome is one of the main causes of intellectual disability in children. It occurs in every community and ethnic group. Several co-morbid conditions are associated with this syndrome. The present study was conducted to determine the frequency of congenital heart disease and thyroid dysfunction in a group of children affected with this genetic disorder. It was a record based retrospective study. A child having specific clinical features and chromosomal analysis showing an extra chromosome 21 was diagnosed as having Down syndrome. Diagnosis of congenital heart disease was based upon results of echocardiography. Thyroid dysfunction was diagnosed when either or both tetraiodothyronine and thyroid-stimulating hormone serum levels were abnormal. Three hundred and fifty cases were enrolled in the study according to the preset criteria for Down syndrome. Two hundred and ten $(60 \%)$ were males and $140(40 \%)$ females showing male to female ratio as 1.5 to 1 . Majority of the children $(55.1 \%)$ presented between 7 months and 24 months of age. Congenital heart defects were found in $41.8 \%$ of the cases. Ventricular septal defect was the most common, $41 \%$. Thyroid dysfunction was found in $22 \%$ $(n=60)$ of the cases of which $5.9 \%(n=16)$ had hypothyroidism. In conclusion, the frequency of congenital heart disease and thyroid dysfunction in Down syndrome children is high. Early referral of these children to tertiary health care facilities is emphasized as timely detection and management of these comorbid conditions will help in reducing the morbidity and mortality in this group of children.

Key words: Down syndrome, heart disease, thyroid disease, Pakistan.

Down syndrome (DS) is a common chromosomal disorder and is the leading genetic cause of low cognitive and physical development in children. ${ }^{1}$ It is also known as trisomy 21 and is caused by the presence of one extra copy of chromosome 21 in human karyotype. In a majority of the cases the extra chromosome 21 appears due to abnormal chromosomal segregation during meiosis resulting in unbalanced gamete formation. Less commonly, the extra copy of chromosome 21 is due to chromosomal translocation either de novo or inherited from mother or father. A small percentage of children with DS are mosaic for trisomy 21 originating during early phase of cell division of the zygote. ${ }^{2}$

Down syndrome was first reported by a British Physician, John Langdon Down ${ }^{3}$, in 1866. However, chromosomal basis of this genetic disorder was reported late in 1959 by Lejeune and associates. ${ }^{4}$ This syndrome occurs in every race and ethnic group.

There is substantial difference of birth prevalence of DS between developed and developing countries. Even among developed countries the birth prevalence varies depending upon mean maternal age and practice of 
antenatal diagnosis of DS and termination of affected pregnancies. The birth prevalence of DS is 1 in 733 live births in the USA ${ }^{5}, 1$ in 449 in the United Arab Emirates (UAE) ${ }^{6}$ and 1 in 300 in Pakistan. ${ }^{7}$ Advanced maternal age at conception appears to be the major contributing factor for the increased incidence of DS in less developed countries like Pakistan and UAE.

DSchildren usually present with developmental delay and characteristic dysmorphic features. Several other morbid conditions are also associated with this disorder, like congenital heart disease (CHD), hypothyroidism, congenital anomalies of the gastrointestinal tract, sleep apnea, Hirschsprung disease, congenital dislocation of hip, subluxation of atlanto-axial joint, acute megakaryocytic leukemia and Alzheimer disease. ${ }^{8}$

CHD has strong association with DS and is the main cause of mortality within first two years of life. ${ }^{1}$ The prevalence of this congenital anomaly varies in children with DS from country to country and among different regions of the same country depending upon the size and age of study population. A group survey of children with DS in Brazil $^{9}$ has reported the prevalence of CHD as $46.8 \%$. However, a lower prevalence is reported from Pakistan ${ }^{10}$, i.e. $34.9 \%$.

The frequency of different types of structural congenital cardiac lesions in DS varies in different studies conducted around the world. Based upon a group of 1193 children Elmagrpy and co-workers ${ }^{11}$ from Libya reported the combine lesions the most common (35\%), followed by atrial septal defect (ASD) as 23.3\%, atrio-ventricular septal defect (AVSD) as $19.2 \%$, and ventricular septal defect (VSD) as $14.1 \%$. Freeman and associates ${ }^{12}$ from the United states of America (USA) have reported a different spectrum of CHD in DS children. Of the 865 echo diagnosed cases, $32.6 \%$ had VSD, $31.6 \%$ ASD, $31.4 \%$ AVSD, and $2.7 \%$ isolated cases of tetralogy of Fallot.

A substantial proportion of children with DS have thyroid dysfunction; hypothyroidism being more common than hyperthyroidism. A dual sampling study from community and rehabilitation centres for disabled children from
Kuwait has reported the prevalence of thyroid dysfunction as $55.2 \% .{ }^{13}$ A lower percentage of thyroid malfunctioning $(28.1 \%)$ is reported in a DS group from Turkey. ${ }^{14}$ The objective of this study was to explore the spectrum of CHD and thyroid dysfunction among DS children referred to the Children's Hospital, Lahore, Pakistan, from $1^{\text {st }}$ June 2010 to $31^{\text {st }}$ December 2016 and compare this information with other national and international studies.

\section{Material and Methods}

\section{Study Setting}

This record based retrospective study was conducted at the Department of Medical Genetics, the Children's Hospital and the Institute of Child Health, Lahore, Pakistan. Informed consent for karyotyping of the child and utilization of relevant clinical data for storage and publication was taken from each family who visited the cytogenetic laboratory of this department. The common clinical entities referred for karyotyping were DS, children with dysmorphic features other than DS, children with abnormal sex development, females with short stature, females with primary amenorrhea, females with recurrent abortions and others.

\section{Case Ascertainment}

After taking the permission from the Hospital Ethical Committee/Institutional Review Board (No. 36/CH/ICH, dated: 10/11/2017), the files of all patients with DS visiting the cytogenetic laboratory from $1^{\text {st }}$ June 2010 to $31^{\text {st }}$ December 2016 were reviewed. Demographic information including age and sex of index case, consanguinity of the parents, results of echocardiography, results of chromosomal analysis and thyroid profile (serum tetraiodothyronine (T4) and thyroidstimulating hormone (TSH)) was retrieved and transferred onto datasheets. For karyotyping, blood sample of 3-5 cc was collected from the peripheral vein of each patient. The cell cultures were incubated for 72 hours at $37^{\circ} \mathrm{C}$. For the preparation of metaphase slides, the chromosomes were harvested followed by giemsa staining. The analyses of metaphases were completed following ISCN protocol. ${ }^{15}$ Serum T4 and TSH levels were 
assessed by ACCESS-2 Immunodiagnostic system (BECKMAN COULTER) using Chemiluminescence Technology. Diagnosis of CHD was based upon results of echocardiography carried by the consultant cardiologist trained in echocardiography.

\section{Definitions}

A child having specific clinical features and chromosomal analysis showing an extra chromosome 21 was diagnostic for DS. Age of the child was ascertained in months and years as told by the parents. A marriage was said to be consanguineous if the spouses had at least one ancestor in common. The upper limit of consanguinity was third cousin as beyond this the value of coefficient of inbreeding is almost zero. ${ }^{1}$ Children were grouped as euthyroid, hyperthyroid and having compensated and uncompensated hypothyroidism on the basis of their serum T4 and TSH levels. Euthyroid was diagnosed if T4 and TSH values were within normal range. Hyothyroidism was declared if T4 level was low and TSH normal or high. Compensated hypothyroidism was considered if T4 was normal with increased level of TSH. In case of hyperthyroidism T4 was high with low or normal value of TSH. This classification has also been used by other researchers. ${ }^{16}$

\section{Statistical Analysis}

All the collected data were entered into the software Statistical Package for the Social Sciences (SPSS) version 22. The different age groups and gender were presented in frequencies and percentages in table forms. Group comparison was made by using Chisquare test or student-t test whichever was appropriate. $\mathrm{P}<0.05$ was taken as significant.

\section{Results}

Three hundred and fifty cases were enrolled in the study according to the preset criteria for DS. Two hundred and ten $(60 \%)$ children were male and 140 (40\%) females showing male to female ratio as 1.5 to 1 . Majority of the children $(55.1 \%, \mathrm{n}=193)$ presented between 7 to 24 months of age (Table I). In 138 children $(39.4 \%)$ the parents were consanguineously married.

Among the 350 cases regular trisomy $(47, \mathrm{XX}+21$ or $47, \mathrm{XY}+21)$ was found in 338 children (96.6\%), translocations (either $14 \mathrm{q} ; 21 \mathrm{q}$ or $21 \mathrm{q} ; 21 \mathrm{q})$ in 10 children $(2.8 \%)$ and 2 male children (0.6\%) were mosaic $(46, \mathrm{XY} / 47, \mathrm{XY}+21)$ (Table II).

Among 10 cases of chromosomal translocations, 6 cases had denovo change while in four cases either one of the parents was carrier (father and mother in two cases each). In 21q;21q translocation, parents' chromosomal analysis was normal.

Results of echocardiography were available for 280 children (80\%) (168 males and 112 females); of those 117 had abnormal findings revealing the frequency of CHD as $41.8 \%$.

Table III presents the frequency of different categories of CHD in 117 cases. VSD was the most common $(41 \%)$ followed by patent ductus arteriosus (PDA) (15.4\%). All cardiac lesions were uniformly more common in female children except VSD which was significantly more common among males $(\mathrm{p}<0.01)$.

Results of thyroid function tests (serum T4 and TSH levels) were available for 272 children.

Table I. Sex and Age Distribution of Study Population.

\begin{tabular}{|c|c|c|c|c|}
\hline \multirow{2}{*}{ Sex } & \multicolumn{3}{|c|}{ Age in Months } & \multirow{2}{*}{ Total } \\
\hline & 0 - 6 Months & 7- 24 Months & 25 Months to 18 years & \\
\hline \multirow{2}{*}{ Male } & 75 & 110 & 25 & 210 \\
\hline & $66.4 \%$ & $57.0 \%$ & $56.8 \%$ & $60 \%$ \\
\hline \multirow{2}{*}{ Female } & 38 & 83 & 19 & 140 \\
\hline & $33.6 \%$ & $43.0 \%$ & $43.2 \%$ & $40 \%$ \\
\hline \multirow{2}{*}{ Total } & 113 & 193 & 44 & 350 \\
\hline & $100 \%$ & $100 \%$ & $100 \%$ & $100 \%$ \\
\hline
\end{tabular}


Table II. Three Different Types of Chromosomal Aberrations in the Study Population.

\begin{tabular}{|c|c|c|c|}
\hline \multirow{2}{*}{ Chromosomal aberration } & \multicolumn{2}{|c|}{ Gender } & \multirow{2}{*}{ Total (\%) } \\
\hline & Male & Female & \\
\hline Regular trisomy & 203 & 135 & $338(96.6 \%)$ \\
\hline Translocations & 5 & 5 & $10(2.8 \%)$ \\
\hline Mosaic & 2 & 0 & $2(0.6 \%)$ \\
\hline Total & 210 & 140 & 350 (100\%) \\
\hline
\end{tabular}

Table III. Frequency and Percentage of Different Types of Cardiac Lesions in Children with DS ( $\mathrm{n}=117)$.

\begin{tabular}{lccc}
\hline \multirow{2}{*}{ Lesion } & \multicolumn{2}{c}{ Sex } & \multirow{2}{*}{ Number (Percentage) } \\
\cline { 2 - 3 } & Male & Female & \\
\hline Ventricular septal defect* & 32 & 16 & $48(41.0 \%)$ \\
Patent ductus arteriosus & 7 & 11 & $18(15.4 \%)$ \\
Atrio-ventricular septal defect & 6 & 8 & $14(12.0 \%)$ \\
Atrial septal defect & 4 & 6 & $10(8.5 \%)$ \\
Pulmonary hypertension & 3 & 5 & $8(6.8 \%)$ \\
Pulmonary stenosis & 2 & 3 & $5(4.3 \%)$ \\
Pericardial effusion & 0 & 1 & $1(0.8 \%)$ \\
Combine (VSD\&PDA) & 1 & 4 & $5(4.3 \%)$ \\
Combine (VSD\&ASD) & 1 & 2 & $3(2.6 \%)$ \\
Combine (AVSD\&PDA) & 1 & 2 & $3(2.6 \%)$ \\
Combine (VSD\&bilateral superior vena-cava) & 0 & 1 & $1(0.8 \%)$ \\
Combine (VSD,PS\&double outlet right ventricle) & 0 & 1 & $1(0.8 \%)$ \\
\hline Total & 57 & 60 & $117(100 \%)$ \\
\hline VSD Venticulann
\end{tabular}

$\mathrm{VSD}=$ Ventricular septal defect, $\mathrm{PDA}=$ Patent ductus arteriosus,

$\mathrm{AVSD}=$ Atrio-ventricular septal defect, $\mathrm{ASD}=$ Atrial septal defect, $\mathrm{PS}=$ Pulmonary stenosis

*Difference of frequency of VSD between males vs females, $\mathrm{p}<0.01$.

Categorical data for T4 and TSH levels against gender and age are shown in Table IV. Thyroid dysfunction was found in 60 children $(22 \%)$. Sixteen children $(5.9 \%)$ had low levels of T4 with high or normal level of TSH suggesting hypothyroidism. Compensated hypothyroidism (raised TSH value in the face of normal T4 level) was observed in 34 cases (12.5\%). Hyperthyroidism (high levels of T4) was present in 10 cases $(3.7 \%)$.

A comparison of the frequency and patterns of CHD and thyroid dysfunction between our cohort and other studies from different countries around the world is shown in Tables $\mathrm{V}$ and IV.

\section{Discussion}

The present study was conducted in the genetic department of a tertiary care pediatric establishment in the province of Punjab. The Punjab is the second large province of Pakistan with population of 110 million. ${ }^{17}$ The DS patients in the present study were referred from different hospitals from all over the province thus providing a fairly representative data on the frequency and pattern of CHD and thyroid dysfunction in DS children in this region.

The early presentation of DS to the health facility for echocardiography and thyroid 
Table IV. Serum T4 Level and Corresponding Serum TSH Level in Six Groups of Children with DS according to gender and age distribution $(n=272)$.

\begin{tabular}{|c|c|c|c|c|c|c|c|c|c|}
\hline \multirow{3}{*}{$\begin{array}{l}\text { Group } \\
\#\end{array}$} & \multirow{3}{*}{$\begin{array}{l}\text { Serum } \\
\text { T4 level }\end{array}$} & \multirow{3}{*}{$\begin{array}{l}\text { Serum } \\
\text { TSH } \\
\text { level }\end{array}$} & \multirow{3}{*}{$\begin{array}{l}\text { Number } \\
\text { of } \\
\text { Children }\end{array}$} & \multicolumn{6}{|c|}{ Gender and Age Distribution } \\
\hline & & & & \multicolumn{3}{|c|}{ Male } & \multicolumn{3}{|c|}{ Female } \\
\hline & & & & 0-6 mon & $7-24$ mon & $\begin{array}{c}25 \text { mon- } \\
18 \text { yrs }\end{array}$ & $0-6$ mon & $7-24$ mon & $\begin{array}{c}25 \text { mon- } \\
18 \text { yrs }\end{array}$ \\
\hline \multirow[t]{2}{*}{1} & \multirow[t]{2}{*}{ Normal } & \multirow[t]{2}{*}{ Normal } & 212 & & $114(74.0 \%)$ & & & $98(83.0 \%)$ & \\
\hline & & & $(77.9 \%)$ & $39(34.2 \%)$ & $59(51.7 \%)$ & $16(14.0 \%)$ & $30(30.6 \%)$ & $52(53.1 \%)$ & $16(16.3 \%)$ \\
\hline \multirow[t]{2}{*}{2} & \multirow[t]{2}{*}{ Normal } & \multirow[t]{2}{*}{ High } & 34 & & $26(16.9 \%)$ & & & $8(6.8 \%)$ & \\
\hline & & & $(12.5 \%)$ & $8(30.8 \%)$ & $14(53.8 \%)$ & $4(15.4 \%)$ & $2(25.0 \%)$ & $4(50.0 \%)$ & $2(25.0 \%)$ \\
\hline \multirow[t]{2}{*}{3} & \multirow[t]{2}{*}{ Low } & \multirow[t]{2}{*}{ High } & 6 & & $4(2.6 \%)$ & & & $2(1.7 \%)$ & \\
\hline & & & $(2.2 \%)$ & $1(25.0 \%)$ & $3(75.0 \%)$ & & $1(50.0 \%)$ & $1(50.0 \%)$ & \\
\hline \multirow[t]{2}{*}{4} & \multirow[t]{2}{*}{ Low } & \multirow[t]{2}{*}{ Normal } & 10 & & $4(2.6 \%)$ & & & $6(5.1 \%)$ & \\
\hline & & & $(3.7 \%)$ & $1(25.0 \%)$ & $2(50.0 \%)$ & $1(25.0 \%)$ & $1(16.7 \%)$ & $3(50.0 \%)$ & $2(33.3 \%)$ \\
\hline \multirow[t]{2}{*}{5} & \multirow[t]{2}{*}{ High } & \multirow[t]{2}{*}{ Normal } & 4 & & & & & $4(3.4 \%)$ & \\
\hline & & & $(1.5 \%)$ & & & & $2(50.0 \%)$ & $2(50.0 \%)$ & \\
\hline \multirow[t]{4}{*}{6} & \multirow[t]{2}{*}{ High } & \multirow[t]{2}{*}{ low } & 6 & & $6(3.9 \%)$ & & & & \\
\hline & & & $(2.2 \%)$ & $2(33.3 \%)$ & $4(66.7 \%)$ & & & & \\
\hline & \multirow{2}{*}{\multicolumn{2}{|c|}{ Total }} & 272 & & $154(56.6 \%)$ & & & $118(43.4 \%)$ & \\
\hline & & & $(100 \%)$ & $51(33.1 \%)$ & $82(53.2 \%)$ & $21(13.6 \%)$ & $36(30.5 \%)$ & $62(52.5 \%)$ & $20(17.0 \%)$ \\
\hline
\end{tabular}

Reference values: (Serum T4: 0.54-1.24 $\mu \mathrm{IU} / \mathrm{ml}$ ) (Serum TSH: 0.34-5.6 $\mu \mathrm{IU} / \mathrm{ml}$ )

function testing is important for timely intervention. In the present study, $32.3 \%$ of the children $(n=113)$ were 6 months or younger when brought to the tertiary health care. This is in contrast with one report from Brazil $^{9}$ where $63.8 \%$ of the DS patients were evaluated for cardiac lesions before 6 months of age.

The gold standard for the diagnosis of DS is still chromosomal analysis. The conventional method of karyotyping by using G-banding is still used in most of the cytogenetic laboratories worldwide. ${ }^{18}$ The same technique of karyotyping was used for our study group. However, DS and other trisomies can also be diagnosed by using special probes in florescence in-situ hybridization (FISH) technique. FISH is superior in the diagnosis of chromosomal aberrations as it is rapid, more sensitive, and less laborious as compared to the ordinary banding techniques. ${ }^{19}$ Regular trisomy 21 was the most common chromosomal aberration found in the present study and this finding is consistent with results of other studies conducted in Pakistan ${ }^{10}$ and abroad. ${ }^{20}$
Chromosomal analysis of each case of DS is followed by a session of genetic counseling to explain the results of the test. This is particularly imperative if a child is found to be having chromosomal translocation. ${ }^{1}$ Chromosomal analyses of parents were carried for all 10 cases of translocations and results explained to the parents for risk of recurrence and possible antenatal diagnosis in next pregnancy.

In $39.4 \%$ of the children with DS in the present study the parents were consanguineously married. This proportion of consanguinity is significantly lower $(\mathrm{p}<0.01)$ as compared to the general population of same areas of Punjab province, i.e. $58.5 \% .^{21}$ Similar findings have also been reported by two independent groups of researchers in 2013 from Iraq ${ }^{22}$ and Iran. ${ }^{23}$ Contrary to this finding an association of parents' consanguinity and emergence of DS was observed in a North American study. ${ }^{24} \mathrm{We}$ may conclude from the above studies that in the interest of public health the DS prenatal diagnostic testing be offered to all embryos regardless of parents' familial relationship. 


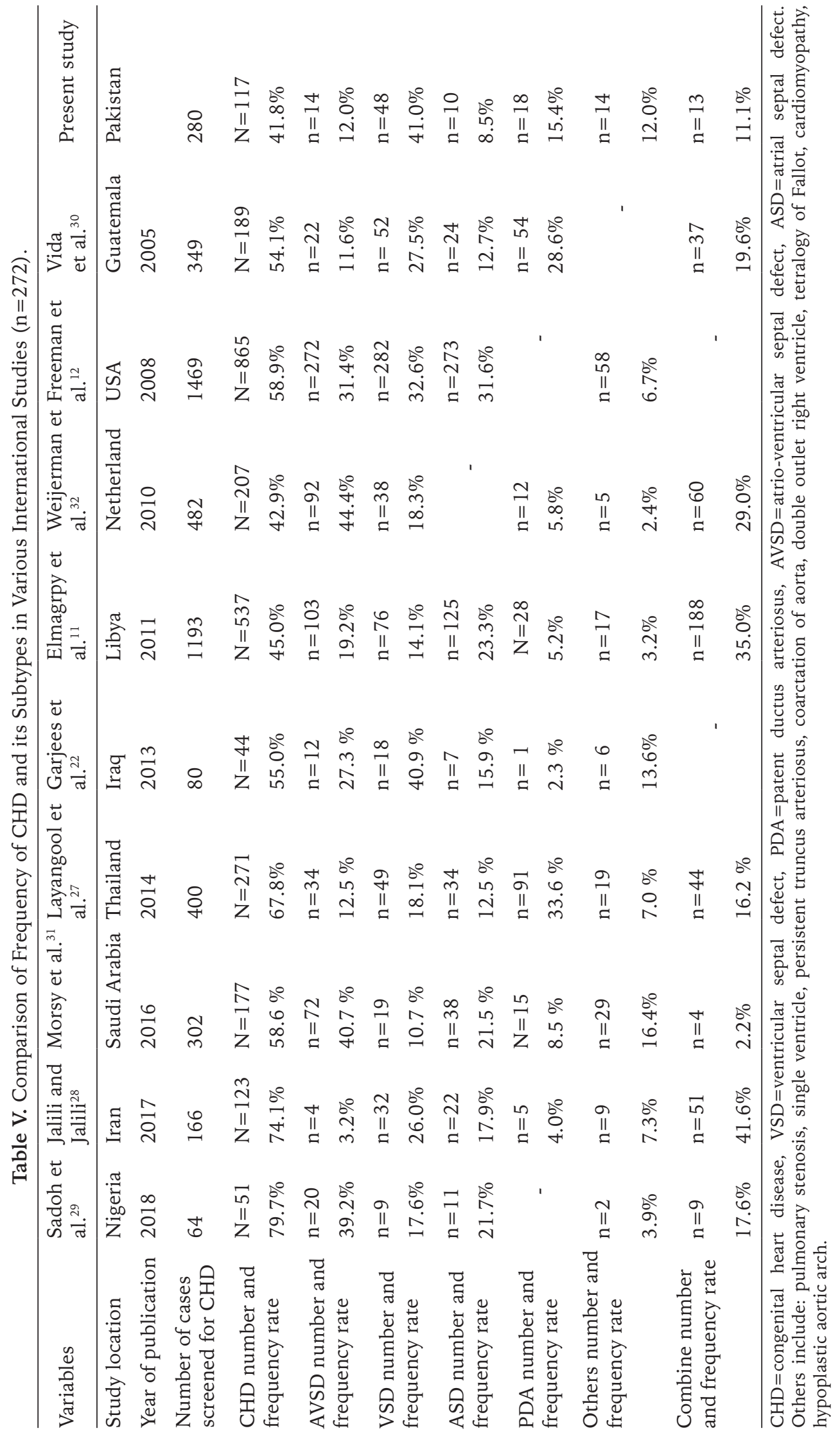




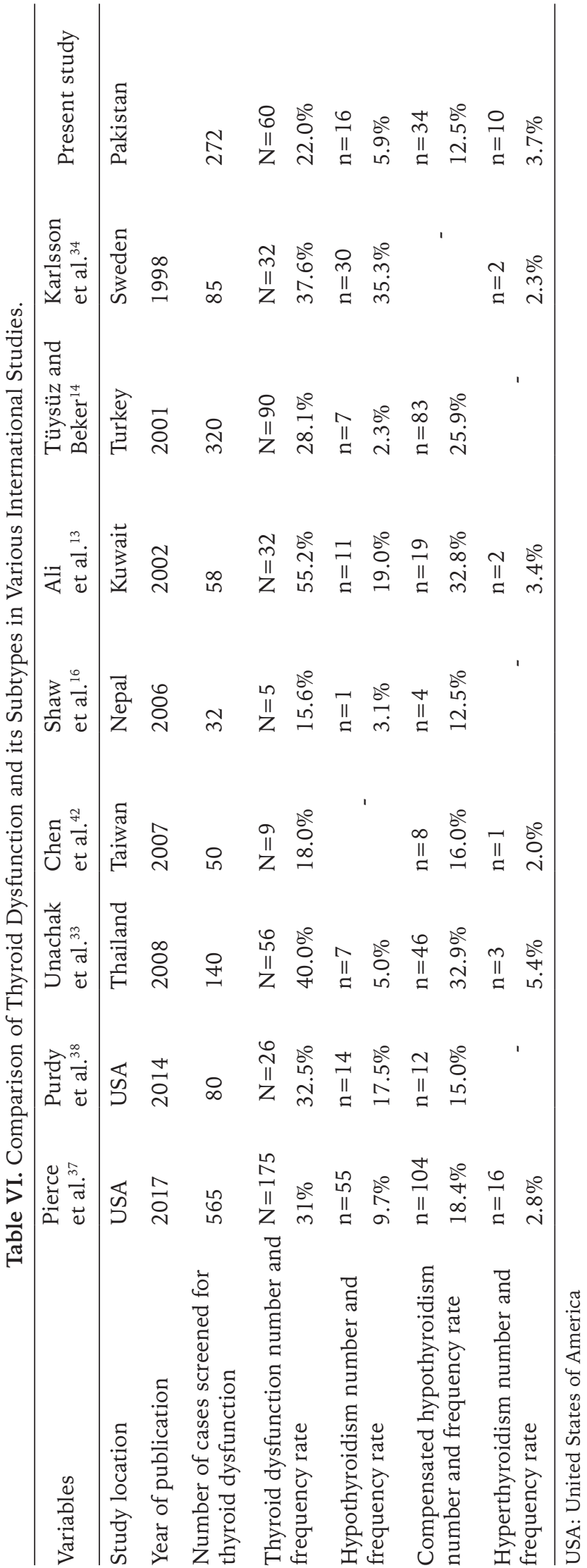

Several diagnostic modalities are used for cardiac lesions in children with DS. Clinical findings suggestive of CHD are cyanosis, tachypnea, tachycardia, abnormal precardial impulse, or a murmur. However, in some cases of DS particularly in neonates there may not be any clinical signs of an underlying cardiac lesion. So, other diagnostic methods like chest radiograph, electrocardiography, echocardiography, cardiac catheterization, doppler color flow measurements, operative notes, autopsy findings have been adopted. ${ }^{25,26}$ In the present study electrocardiography and echocardiography were performed for all cases.

The prevalence of CHD in the present study population was $41.8 \%$. This figure is higher when compared to one previous study conducted in Pakistan ${ }^{10}$ on this subject, which showed CHD as $34.9 \%$. Higher prevalent figures of CHD in DS children have also been reported from other countries like Thailand ${ }^{27}(67.8 \%)$, $\operatorname{Iran}^{28}(74.1 \%)$ and Nigeria ${ }^{29}(79.7 \%)$.

International literature review highlights quite striking results of subtypes of CHD in DS populations as shown in Table V. In the present study, the most common cardiac lesion was isolated VSD, $41 \%$. This figure is comparable with one study from $\operatorname{Iraq}^{22}$, i.e. $40.9 \%$. The second most common type of cardiac lesion in the present study is PDA (15.4\%). This finding is inconsistent with results of other studies. For example, the frequency of this lesion was $2.3 \%$ in the Iraqi study ${ }^{22}$ and $33.6 \%$ in a study from Thailand. ${ }^{27}$ Interestingly two DS studies, one from Nigeria $^{29}$ and other from the USA $^{12}$ have not shown any isolated case of PDA.

Of the $41.8 \%$ children with CHD in the present series $12 \%$ had AVSD. This frequency rate is consistent with two other international studies, i.e. one from Thailand ${ }^{27}$ and other from Guatemala. ${ }^{30}$ Those studies have reported the proportions of AVSD as $12.5 \%$ and $11.6 \%$ respectively. However, 
some investigators have reported high figures of this congenital cardiac anomaly $(39.2 \%$ to $44.4 \%) .{ }^{29,31,32}$

In the present study, a majority of the children had single isolated cardiac lesions $(88.9 \%)$. A higher proportion of multiple cardiac birth defects in DS children is reported by Elmagrpy and associates ${ }^{11}$ from Libya, i.e. $35 \%$, and Jalili and Jalili ${ }^{28}$ from Iran, i.e. $41.6 \%$. The Thai study ${ }^{27}$ has shown 6 cases of tetralogy of Fallot and 2 cases of coarctation of aorta. The American study ${ }^{12}$ has shown tetralogy of Fallot as $2.7 \%$. These lesions were not found in the present study population.

Abnormal thyroid function in DS children was detected in $22 \%(n=60)$ of the cases in the present study. Higher figures of this comorbid condition with DS has been reported by Ali et al. ${ }^{13}$ from Kuwait and Unachak and coworkers ${ }^{33}$ from Thailand. A longitudinal cohort of 85 individuals with DS (age ranged from 1 to 25 years) from Sweden revealed thyroid dysfunction in $37.6 \%$ of the cases. ${ }^{34}$ The annual thyroid screening in Swedish cohort also revealed increased risk of developing thyroid dysfunction with increasing age in DS children. Iughetti and co-workers ${ }^{35}$ from Italy have also reported that the prevalence of normal thyroid function in patients with DS significantly decreased from $70 \%$ to $51 \%$ $(\mathrm{p}<0.001)$ through a 10-years follow-up period. These researchers have suggested a genetic predisposition and a propensity to acquired autoimmune disorder the possible cause for this progressive worsening of thyroid function, though the exact etiology remains unclear.

Diagnosis of overt hypothyroidism in children with DS is important as it requires timely treatment in the form of thyroxin replacement therapy to save the child from further intellectual deterioration. ${ }^{36}$ In the present study $5.9 \%(n=16)$ of the cases suffered from hypothyroidism and this figure is concordance with one study from Thailand. ${ }^{33}$ Shaw and associates ${ }^{16}$ from Nepal and Tüysüz and Beker ${ }^{14}$ from Turkey have shown low proportions of hypothyroidism in DS populations, i.e. $3.1 \%$ and $2.3 \%$ respectively. Figures between $9.7 \%$ and $35.3 \%$ have also been published. 13,34,37,38 According to an Egyptian study, hypothyroidism was significantly more common in DS children with translocations and mosaic karyotypes than in the regular trisomy. ${ }^{20}$ However, in the present study, hypothyroidism was evenly distributed among different categories of karyotypes.

Compensated hypothyroidism also known as subclinical hypothyroidism or isolated thyrotropinaemia is a peculiar type of thyroid dysfunction observed more frequently in DS population. Its frequency varies from $12.5 \%$ to $32.9 \%$ as shown in different studies (Table VI). The figure of present study touches the lower proportion of this variation. In most cases, compensated hypothyroidism is asymptomatic and is detected upon laboratory testing to screen thyroid functions. The cause of compensated hypothyroidism is unclear. Autoimmunity is hypothesized by several researchers. ${ }^{39}$ The incidence of conversion of compensated hypothyroidism to overt hypothyroidism is estimated to be less than $50 \%$. The natural course of compensated hypothyroidism is not consistent, and that is the reason many authors are in favor of not treating this hormonal derangement unless the serum level of T4 declines below the lower limit. ${ }^{40,41}$ The prevalence of hyperthyroidism in DS is less as compared to that of hypothyroidism in almost all of the different studies conducted worldwide (Table VI). The present study also shows similar results.

In conclusion, as shown in tables $\mathrm{V}$ and IV, there is large variation in the frequency rates of CHD and thyroid dysfunction in different international studies. Even within the same country the frequency rates of these comorbid conditions vary from region to region. This global and indigenous heterogeneous distribution of these ailments involve multiple genetic and environmental factors like ethnicity, consanguinity, geographical area, founder effect, study design, age group, or method of case ascertainment. One of the limitations of this study was retrospective design. The diagnosis of CHD and results of thyroid function tests were not available for $20 \%$ and $22 \%$ of the cases respectively. But our sample size is fairly large as compared to several other studies. ${ }^{13,16,29,42}$ 
The treatment of DS as such, like several other chromosomal aberrations, is not available but early initiation of habilitation certainly helps to attain several skills in these children. Every child with DS needs a structured medical program for follow up with special reference to the diagnosis and management of $\mathrm{CHD}$ and thyroid dysfunction. ${ }^{43}$ If not detected and managed early in life the additive effects of these conditions may lead to further amplification of the clinical problems of these children. The early management of these ailments will certainly help in reducing morbidity and mortality in this group of children and thus lessen the burden on tertiary care hospitals in a resource constraint country like Pakistan.

\section{Acknowledgement}

The authors are thankful to Prof Shakila Zaman for her helpful comments on the manuscript.

\section{REFERENCES}

1. Nussbaum RL, McInnes RR, Willard HF. In: Thompson \& Thompson Genetics in Medicine (8th ed.), Philadelphia, PA: Elsevier Publishers, Chapter 6, 2016: 178-183.

2. Jyothy A, Kumar KSD, Rao GNM, et al. Parental age and the origin of extra chromosome 21 in Down syndrome. J Hum Genet 2001; 46: 347-350.

3. Down JLH. Observations on an ethnic classification of idiots. London Hospital Reports 1866; 3: 259-262.

4. Lejeune J, Turpin R, Gautier M. Le mongolisme premier exemple d'aberration autosomique humaine. Ann Genet 1959; 1: 41-49.

5. Lee B. Down syndrome and other abnormalities of chromosome Number. In: Kliegman RM, Stanton BF, Schor NF, St Geme III JW, Behrman RE (eds.) Nelson Text Book of Pediatrics. (20th ed). Philadelphia, PA: Elsevier, 2016: 610-616.

6. Murthy SK, Malhotra AK, Mani S, et al. Incidence of Down syndrome in Dubai, UAE. Med Princ Pract 2007; 16: 25-28.

7. Yaqoob M, Bashir A, Tareen K, et al. Severe mental retardation in 2 to 24-month-old children in Lahore, Pakistan: a prospective cohort study. Acta Paediatr 1995; 84: 267-272.

8. Jones KL, Jones MC, del Campo M. Chromosomal Abnormality Syndromes Identifiable on Routine Karyotype. In: Smith's Recognizable Pattern of Human Malformation (7th ed). Philadelphia: Elsevier Saunders, 2013: 7-13.
9. Vilas Boas LT, Albernaz EP, Costa RG. Prevalence of congenital heart defects in patients with Down syndrome in the municipality of Pelotas, Brazil. J Pediatr (Rio J) 2009; 85: 403-407.

10. Ahmed I, Ghafoor T, Samore NA, Chattha MN. Down syndrome: clinical and cytogenetic analysis. J Coll Physicians Surg Pak 2005; 15: 426-429.

11. Elmagrpy Z, Rayani A, Shah A, Habas E, Aburawi EH. Down syndrome and congenital heart disease: why the regional difference as observed in the Libyan experience? Cardiovasc J Afr 2011; 22: 306-309.

12. Freeman SB, Bean LH, Allen EG, et al. Ethnicity, sex, and the incidence of congenital heart defects: a report from the National Down Syndrome Project. Genet Med 2008; 10: 173-180.

13. Ali FE, Bayoumy HA, Mohammad ASR, Al-Busairi WA, Al-Othman ANA. Thyroid function in Kuwaiti subjects with Down's syndrome. Med Princ Pract 2002; 11: 206-209.

14. Tüysüz B, Beker DB. Thyroid dysfunction in children with Down's syndrome. Acta Paediatr 2001; 90: 1389-1393.

15. Shaffer LG, Tommerup N. (eds). An International System for Human Cytogenetic Nomenclature (ISCN). Basel: S. Karger Publishers, 2005.

16. Shaw CK, Thapalial A, Nanda S, Shaw P. Thyroid dysfunction in Down syndrome. Kathmandu Uni Med J (KUMJ) 2006; 4: 182-186.

17. Pakistan Bureau of Statistics. Government of Pakistan. Sixth Population and Housing Census Year 2017.

18. Benn PA, Perle MA. Chromosome staining and banding techniques. In: Rooney DE, Czepulkowski BH (eds). Human Cytogenetics A Practical Approach. Oxford, Washington DC: IRL Press, 1986: 57-84.

19. Gekas J, van den Berg DG, Durand A, et al. Rapid testing versus karyotyping in Down's syndrome screening: cost-effectiveness and detection of clinically significant chromosome abnormalities. Eur J Hum Genet 2011; 19: 3-9.

20. El-Gilany AH, Yahia S, Shoker M, El-Dahtory F. Cytogenetic and comorbidity profile of Down syndrome in Mansoura University Children's Hospital, Egypt. Indian J Hum Genet 2011; 17: 157163

21. Riaz HF, Mannan S, Malik S. Consanguinity and its socio-biological parameters in Rahim Yar Khan District, Southern Punjab, Pakistan. J Health Popul Nutr 2016; 35: 14.

22. Garjees NA, Muhsin ARA. Congenital heart disease in children with Down syndrome in Duhok city. Pak Pediatr J 2013; 37: 212-216.

23. Rezayat AA, Nazarabadi MH, Andalibi MSS, et al. Down syndrome and consanguinity. J Res Med Sci 2013; 18: 995-997. 
24. deBraekeleer M, Landry T, Cholette A. Consanguinity and kinship in Down syndrome in Saguenay LacSaint-Jean (Québec). Ann Genet 1994; 37: 86-88.

25. Figueroa JR, del Pozzo Magaña B, Hach JLP , Jiménez CC, Urbina RC. Heart malformations in children with Down syndrome. Rev Esp Cardiol 2003; 56: 894-899.

26. Abbag FI. Congenital heart diseases and other major anomalies in patients with Down syndrome. Saudi Med J 2006; 27: 219-222.

27. Layangool T, Sangtawesin C, Kirawittaya T, Prompan W, Prachasilchai P, Pechdamrongsakul A. Survival analysis of Down syndrome with congenital heart disease: A 5-years registry at QSNICH. J Med Assoc Thai 2014; 97 (Suppl 6): S108-S114.

28. Jalili Z, Jalili C. Congenital heart disease in children with Down syndrome in Kermanshah, West of Iran during 2002 - 2016. Int J Pediatr 2017; 5: 6095-6102.

29. Sadoh WE, Eki-Udoko FE, Isah IA. Profile of clinical features, congenital heart disease and other comorbidities in children with Down syndrome in a tertiary care centre in Nigeria. Sri Lanka J Child Health 2018; 47: 50-55.

30. Vida VL, Barnoya J, Larrazabal LA, Gaitan G, Garcia FM, Castañeda AR. Congenital cardiac disease in children with Down's syndrome in Guatemala. Cardiol Young 2005; 15: 286-290.

31. Morsy MM, Algrigri OO, Salem SS, et al. The spectrum of congenital heart diseases in Down syndrome. A retrospective study from Northwest Saudi Arabia. Saudi Med J 2016; 37: 767-772.

32. Weijerman ME, van Furth AM, van der Mooren MD, et al. Prevalence of congenital heart defects and persistent pulmonary hypertension of the neonate with Down syndrome. Eur J Pediatr 2010; 169: 11951199.

33. Unachak K, Tanpaiboon P, Pongprot Y, et al. Thyroid functions in children with Down's syndrome. J Med Assoc Thai 2008; 91: 56-61.
34. Karlsson B, Gustafsson J, Hedov G, Ivarsson SA, Annerén G. Thyroid dysfunction in Down's syndrome: relation to age and thyroid autoimmunity. Arch Dis Child 1998; 79: 242-245.

35. Iughetti L, Predieri B, Bruzzi P, et al. Ten-year longitudinal study of thyroid function in children with Down's syndrome. Horm Res Paediatr 2014; 82: 113-121.

36. Cebeci AN, Güven A, Yıldız M. Profile of hypothyroidism in Down's syndrome. J Clin Res Pediatr Endocrinol 2013; 5: 116-120.

37. Pierce MJ, LaFranchi SH, Pinter JD. Characterization of thyroid abnormalities in a large cohort of children with Down syndrome. Horm Res Paediatr 2017; 87: 170-178.

38. Purdy IB, Singh N, Brown WL, Vangala S, Devaskar UP. Revisiting early hypothyroidism screening in infants with Down syndrome. J Perinatol 2014; 34 : 936-940.

39. Gibson PA, Newton RW, Selby K, Price DA, Leyland K, Addison GM. Longitudinal study of thyroid function in Down's syndrome in the first two decades. Arch Dis Child 2005; 90: 574-578.

40. Amr NH. Thyroid disorders in subjects with Down syndrome: an update. Acta Biomed 2018; 89: 132139.

41. Sridhar M, Mahadevan S, Vishvanathan L, Subbarayan A. Subclinical hypothyroidism: a prospective observational study from Southern India. Indian Pediatr 2018; 55: 219-221.

42. Chen MH, Chen SJ, Su LY, Yang W. Thyroid dysfunction in patients with Down syndrome. Acta Paediatr Taiwan 2007; 48: 191-195.

43. Bull MJ; Committee on Genetics. Health supervision for children with Down syndrome. Pediatrics 2011; 128: 393-406. 